\title{
Effects of reverse headgear on pharyngeal airway in patients with different vertical craniofacial features
}

\section{Burcu BALOŞ TUNCER Çağrı ULUSOY \\ Cumhur TUNCER \\ Çağrı TÜRKÖZ \\ Selin KALE VARLIK}

Gazi University, Faculty of Dentistry, Department of Orthodontics, Ankara, Turkey.

Declaration of Interests: The authors certify that they have no commercial or associative interest that represents a conflict of interest in connection with the manuscript.

Corresponding Author:

Çağrı Ulusoy

E-mail: culusoy77@yahoo.com

DOI: 10.1590/1807-3107BOR-2015.vol29.0057

Submitted: May 20, 2014

Accepted for publication: Jan 15, 2015

Last revision: Apr 07, 2015

\begin{abstract}
The aim of this study was to investigate the effects of reverse headgear (RH) on pharyngeal airway morphology in two groups of Class III patients with different vertical craniofacial features in comparison with an untreated Class III group. Seventeen subjects (9 males, 8 females; mean age $11.3 \pm 0.98$ years) with optimum vertical growth and 17 subjects (10 males, 7 females, mean age $11.5 \pm 1.1$ years) with a vertical growth pattern treated with a removable intra-oral appliance and a Delaire type facemask were included. An untreated Class III control group of 11 subjects ( 8 males, 3 females, mean age $9.1 \pm 1.1$ years) was included to compare the treated groups. The paired t-test for intragroup and one-way ANOVA for intergroup comparisons were performed. The relationships between changes in the craniofacial morphology and airway were assessed by Spearman correlation analysis. The airway dimensions at the adenoid side and soft palate were increased in the treatment groups compared to the control group $(p<0.05)$. The nasopharyngeal area demonstrated a significant difference in normodivergent and control subjects $(\mathrm{p}<0.05)$. No significant difference was found in the airway morphology due to different vertical features. The effect of $\mathrm{RH}$ treatment on the sagittal airway dimensions revealed no significant difference between different vertical craniofacial features in the short term.
\end{abstract}

Keywords: Orthodontics; Extraoral Traction Appliances; Airway Management.

\section{Introduction}

Maxillary advancement by reverse headgear (RH) has been a major treatment option in young skeletal Class III patients, ${ }^{1,2}$ providing enhancement of maxillary growth and restraint and/or redirection of mandibular growth. ${ }^{3}$ The beneficial effects of $\mathrm{RH}$ on the upper airway dimensions have been demonstrated in previous studies., ${ }^{4,5}$ Airway analysis often included cephalograms, ${ }^{7}$ and their reliability was found to be adequate. ${ }^{8}$

Studies have shown an association between craniofacial morphology and airway dimensions, ${ }^{9,10}$ and there is limited knowledge due to the effect of a steep mandibular plane angle on airway size. ${ }^{11,12,13}$ Reduction in airway space after mandibular setback surgery in Class III patients was declared to be a causative factor in airway obstruction. ${ }^{14}$ Reduced 
airway dimensions are proposed to be related to an increased mandibular plane angle. ${ }^{15,16}$ Hence, there was an interest in whether different vertical craniofacial features evoke differences in airway dimensions. Thus, the aim of this study was to investigate the effects of RH treatment on airway morphology in Class III patients, demonstrating different vertical facial patterns (normodivergent versus hyperdivergent) in comparison with an untreated Class III control group.

\section{Methodology}

Materials for this retrospective study were selected from the files of the Department of Orthodontics, Gazi University, Dentistry Faculty. The study was approved by the Ethical Committee of Gazi University (protocol number: 2014/12544). Patients were included based on the following criteria: (1) RH treatment, (2) skeletal $\left(\mathrm{ANB}<0^{\circ}\right.$ ) and dental Class III malocclusion with maxillary retrusion (SNA $\left.<82^{\circ}\right)$, (3) anterior crossbite, (4) optimal or high mandibular plane angle (SN/GoGn:26-38 ${ }^{\circ}$ or $\left.>38^{\circ}\right)$, (5) no congenital anomalies, (6) presence of good quality cephalograms. Of the 102 patients who fit the above criteria, patients with chronological ages between 9-12 years who were in the prepubertal period (between the $\mathrm{PP}_{2}$ and $\mathrm{MP}_{3 \text { cap }}$ developmental stages) were chosen. ${ }^{17}$ Sample size was calculated with a statistical power of 0.80 , and the number of patients per group was required to be at least 10 . The final treatment groups included 34 patients (15 males, 19 females).

The Reverse Headgear normodivergent (RH-ND) group consisted of 17 subjects ( 9 males, 8 females; mean age $11.3 \pm 0.98$ years) demonstrating optimum vertical growth (SN/GoGn: 26-38 $)$ who were treated with a removable intra-oral appliance with a thickness to open the bite to an edge-to-edge incisal position, with hooks between the lateral incisors and canines, and a Delaire type facemask (Figure 1). The mean treatment time was $9.7 \pm 2.8$ months.

The Reverse Headgear hyperdivergent (RH-HD) group consisted of 17 children (10 males, 7 females, mean age $11.5 \pm 1.1$ years) with increased vertical growth $\left(\mathrm{SN} / \mathrm{GoGn}>38^{\circ}\right)$ who were treated with the

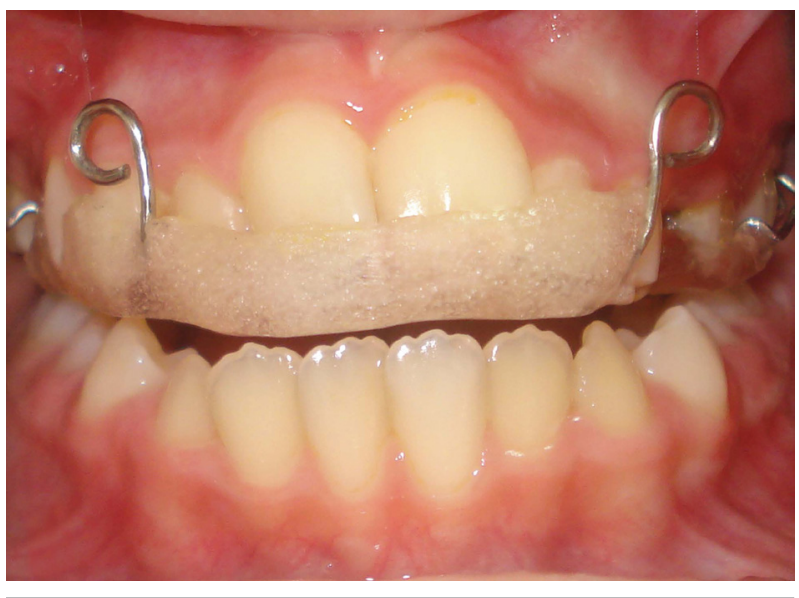

Figure 1. View of intraoral appliance.

same appliance for $10.6 \pm 1.2$ months. Both groups revealed a protraction force of $400-450 \mathrm{~g}$ per side delivered by elastics from the hooks, approximately $30^{\circ}$ below the occlusal plane. ${ }^{18}$ Patients were asked to wear the appliances 14-16 hours per day. All were treated at least to a positive dental overjet before discontinuing treatment.

Control (CNT) group: Data on 11 untreated Class III subjects (8 males, 3 females, mean age $9.1 \pm 1.1$ years), which were collected for a previous study for 12 months, were used.

All cephalograms were taken in natural head position using a Trophy Instrumentarium Cephalometer (Instrumentarium Imaging Co., Tuusula, Finland) at $70 \mathrm{KVp}, 16 \mathrm{mAs}^{-1}$, under standard conditions in the occlusal position, as after a usual swallow. The radiographs were traced on acetate papers and measured manually by the same researcher. Cephalometric measurements are shown in Figure 2A, 2B. Area measurements were performed by the NETCAD for Windows Software Programme (Ulusal Co., Ankara, Turkey), an engineering drawing program. The airway area was divided by the palatal line into the nasopharyngeal area (NA) and oropharyngeal area (OA) (Figure 3). The cephalograms were scanned (Epson Co., Nagano, Japan) using standard conditions. NA and OA were digitized according to the specified points by two different researchers to obtain maximum reliability and agreement. The numerical value of the areas was calculated as units. Fifteen randomly selected 

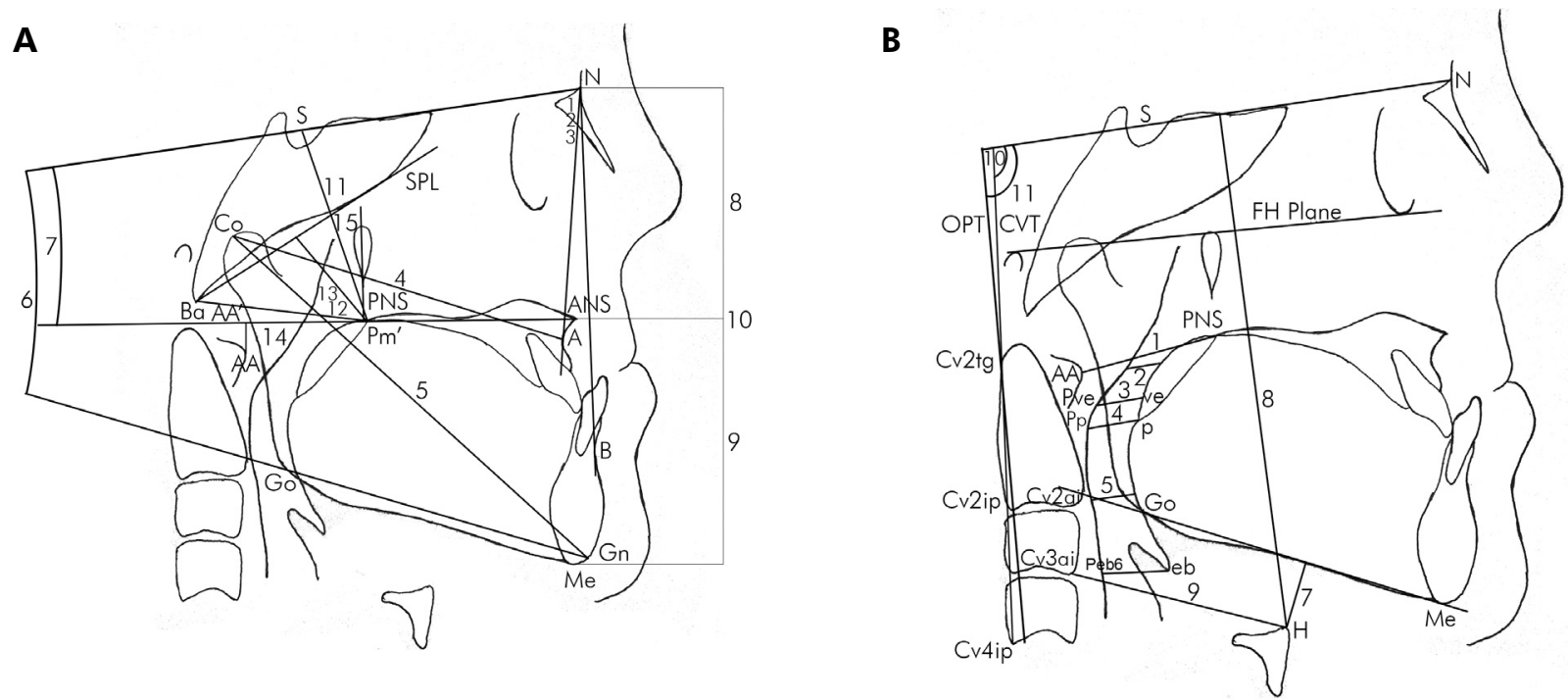

Figure 2. A: Cephalometric analysis of jaws and nasopharynx. (1) SNA; (2) SNB; (3) ANB; (4) Co-A, effective maxillary length; (5) Co-Gn, effective mandibular length; (6) SN-GoGn; (7) SN-PP, palatal plane inclination; (8) N-ANS, upper anterior facial height; (9) ANS-Me, lower anterior facial height; (10) N-Me, total anterior facial height; (1 1) S-PNS, nasopharyngeal height; (12) ad1-PNS, distance from PNS to lower adenoid tissue; (13) ad2-PNS, distance from PNS to upper adenoid tissue; (14) $\mathrm{AA}^{\prime}-\mathrm{Pm}^{\prime}$, distance between the perpendicular intersections of the anterior atlas and pterygomaxillary line along the palatal line; (15) Pm'-SPL, sphenoid line tangent to lower border of sphenoid. B: Cephalometric analysis of oropharynx, hyoid bone and head posture. (1) AA-PNS; (2) SPS, distance from the midpoint of the line from PNS to tip of soft palate to the horizontal counterpart on the posterior pharyngeal wall along parallel line to Frankfurt horizontal (FH) plane; (3) ve-Pve, distance of velum palatinum to the horizontal counterpart on the posterior pharyngeal wall along parallel line to FH plane; (4) MPS, distance from the tip of the soft palate to the horizontal counterpart on the posterior pharyngeal wall along parallel line to FH plane; (5) IPS, distance from the intersection points on the anterior and posterior pharyngeal wall through Cv2ai along parallel line to $\mathrm{FH}$ plane; (6) eb-Peb, distance from vallecula epiglottis to the horizontal counterpart on the posterior pharyngeal wall along parallel line to $\mathrm{FH}$ plane; (7) H-MP, perpendicular distance from hyoid bone to the mandibular plane; (8) H-SN, perpendicular distance from hyoid bone to SN plane; (9) C3-H, distance from the anterio-inferior point of the third cervical vertebra to point $\mathrm{H}$; (10) SN-CVT, downward angle between SN plane and the line through Cv2tg and Cv4ip; (1 1) SN-OPT, downward angle between SN plane and the line through Cv2tg and Cv2ip.

radiographs among all groups were retraced and remeasured by the same researcher 15 days after the first evaluation. Pearson correlation analysis was used to assess the reliability and reproducibility of the variables. The reliability coefficients $\left(\mathrm{r}^{2}\right)$ calculated for each parameter were between 0.91 and 0.97. Data were analyzed with SPSS for Windows, version 20.0 (SPSS Inc., Chicago, USA). The Shapiro-Wilk test was used to check the data normality. Intragroup comparisons were assessed by paired t-test, and the one-way analysis of variance (ANOVA) test was used for intergroup comparisons. The relationship between changes in the pharyngeal airway and craniofacial morphology was evaluated using Spearman correlation analysis. $p<0.05$ was considered to be statistically significant.

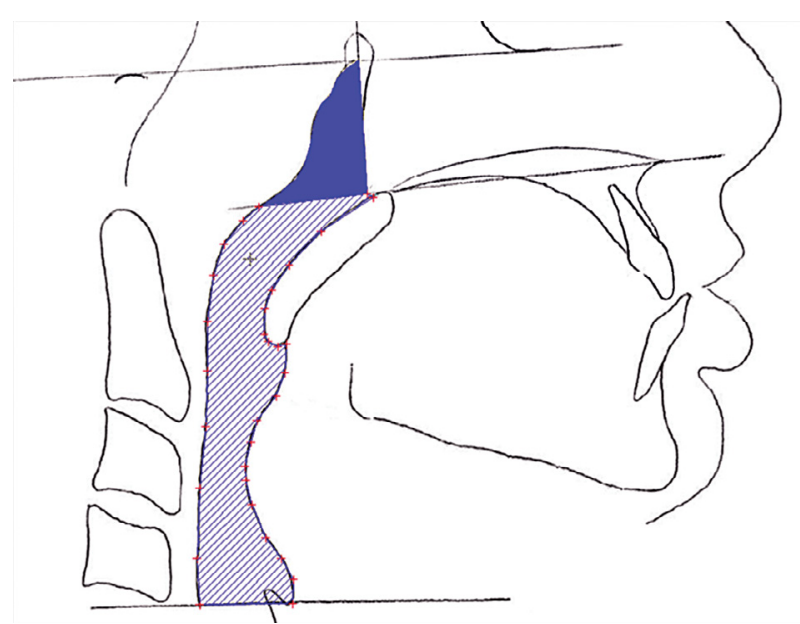

Figure 3. Nasopharyngeal (NA, blue section), oropharyngeal $(\mathrm{OA}$, striped section) areas. 


\section{Results}

The pre- and post-treatment and pre- and post-observation descriptive values and comparison of the changes within each group are presented in Table 1.

Treatment changes in RH-ND group: The maxilla moved forward, as revealed by the increases in SNA and Co-A ( $p<0.01, \mathrm{p}<0.001$, respectively). ANB increased significantly $(p<0.001)$. There were significant increases in Co-Gn $(\mathrm{p}<0.01), \mathrm{N}-\mathrm{ANS}$ $(\mathrm{p}<0.05)$, ANS-Me $(\mathrm{p}<0.001)$ and N-Me $(\mathrm{p}<0.001)$. Nasopharyngeal height, nasopharyngeal airway dimensions (NA), oropharyngeal airway dimensions (OA) and hyoid position were increased (Table 1).

Treatment changes in RH-HD group: Increases in SNA and ANB ( $p<0.01)$, Co-A and Co-Gn $(\mathrm{p}<0.001$, $p<0.01)$ were found. The SN-PP angle decreased at

Table 1. Pre- and post-treatment and observation mean and standard deviation of variables and comparison of the changes.

\begin{tabular}{|c|c|c|c|c|c|c|c|c|c|c|c|c|c|c|c|}
\hline \multirow{3}{*}{ Measurement } & \multicolumn{5}{|c|}{ RH-ND group } & \multicolumn{5}{|c|}{ RH-HD group } & \multicolumn{5}{|c|}{ CNT group } \\
\hline & \multicolumn{2}{|c|}{ Pre-treatment } & \multicolumn{2}{|c|}{ Post-treatment } & & \multicolumn{2}{|c|}{ Pre-treatment } & \multicolumn{2}{|c|}{ Post-treatment } & \multirow[b]{2}{*}{ 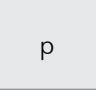 } & \multicolumn{4}{|c|}{ Pre-observation Post-observation } & \\
\hline & Mean & SD & Mean & SD & & Mean & SD & Mean & SD & & Mean & SD & Mean & SD & \\
\hline \multicolumn{16}{|c|}{ Skeletal morphology } \\
\hline $\mathrm{SNA}\left({ }^{\circ}\right)$ & 78.1 & 3.5 & 80.5 & 3.7 & 0.002 & 75.4 & 3.2 & 77.1 & 3.0 & 0.004 & 76.1 & 3.8 & 78.5 & 3.7 & 0.003 \\
\hline $\mathrm{SNB}\left({ }^{\circ}\right)$ & 80.5 & 3.8 & 80.3 & 3.5 & 0.863 & 76.4 & 2.7 & 76.0 & 2.6 & 0.305 & 77.5 & 4.4 & 80.5 & 4.4 & 0.003 \\
\hline $\operatorname{ANB}\left({ }^{\circ}\right)$ & -2.4 & 1.2 & 0.3 & 1.0 & 0.000 & -1.1 & 1.0 & 1.1 & 0.9 & 0.000 & -1.4 & 2.1 & -2.0 & 2.1 & 0.023 \\
\hline $\mathrm{CoA}$ & 83.8 & 4.6 & 88.1 & 4.7 & 0.000 & 83.4 & 6.8 & 88.3 & 7.0 & 0.000 & 77.6 & 3.2 & 79.5 & 3.7 & 0.043 \\
\hline CoGn & 115.8 & 6.0 & 119.4 & 5.5 & 0.001 & 114.5 & 8.2 & 118.6 & 7.5 & 0.001 & 106.2 & 5.9 & 110.0 & 6.7 & 0.008 \\
\hline SNGoGn $\left({ }^{\circ}\right)$ & 32.9 & 2.5 & 33.8 & 2.6 & 0.081 & 40.9 & 2.9 & 40.5 & 3.4 & 0.441 & 36.8 & 5.9 & 35.3 & 5.0 & 0.015 \\
\hline $\mathrm{SN}-\mathrm{PP}\left({ }^{\circ}\right)$ & 7.8 & 3.0 & 6.8 & 2.8 & 0.123 & 9.8 & 3.5 & 8.9 & 3.1 & 0.045 & 7.9 & 2.0 & 8.0 & 3.2 & 1.000 \\
\hline N-ANS & 51.6 & 3.5 & 52.5 & 3.5 & 0.040 & 54.0 & 4.4 & 55.5 & 3.4 & 0.004 & 50.5 & 3.7 & 50.4 & 4.0 & 0.878 \\
\hline ANS-Me & 65.8 & 5.4 & 69.8 & 5.4 & 0.000 & 69.4 & 4.7 & 70.9 & 3.9 & 0.035 & 61.9 & 4.6 & 62.9 & 5.0 & 0.056 \\
\hline $\mathrm{N}-\mathrm{Me}$ & 117.4 & 7.3 & 122.3 & 7.4 & 0.000 & 123.4 & 8.0 & 126.3 & 6.3 & 0.011 & 112.4 & 6.8 & 113.3 & 6.5 & 0.180 \\
\hline \multicolumn{16}{|l|}{ Nasopharynx } \\
\hline S-PNS & 46.5 & 4.5 & 48.5 & 4.2 & 0.000 & 44.8 & 5.4 & 46.2 & 5.3 & 0.008 & 44.6 & 3.6 & 46.4 & 3.8 & 0.007 \\
\hline ad1-PNS & 20.1 & 3.6 & 22.6 & 3.0 & 0.000 & 19.1 & 4.8 & 20.4 & 5.2 & 0.007 & 19.0 & 5.7 & 19.3 & 5.1 & 0.592 \\
\hline ad2-PNS & 18.0 & 5.6 & 20.4 & 4.8 & 0.000 & 18.4 & 4.5 & 20.2 & 3.8 & 0.010 & 15.5 & 4.0 & 16.0 & 3.3 & 0.090 \\
\hline$A A^{\prime}-P m^{\prime}$ & 32.2 & 3.8 & 33.3 & 3.4 & 0.014 & 31.3 & 3.2 & 32.5 & 2.9 & 0.009 & 25.7 & 2.8 & 25.3 & 3.6 & 0.347 \\
\hline $\mathrm{Pm}^{\prime}-\mathrm{SPL}$ & 24.4 & 4.6 & 25.4 & 5.2 & 0.032 & 24.5 & 5.1 & 26.0 & 5.2 & 0.002 & 27.1 & 3.3 & 29.6 & 3.9 & 0.018 \\
\hline NA & 8872 & 4192 & 10353 & 3086 & 0.010 & 9111 & 3044 & 9896 & 2620 & 0.309 & 9140 & 3461 & 8098 & 3545 & 0.155 \\
\hline \multicolumn{16}{|l|}{ Oropharynx } \\
\hline AA-PNS & 32.1 & 3.2 & 33.3 & 3.2 & 0.023 & 31.3 & 3.3 & 32.1 & 3.2 & 0.074 & 31.4 & 3.5 & 31.8 & 2.8 & 0.858 \\
\hline SPS & 12.2 & 1.7 & 13.8 & 1.7 & 0.002 & 12.8 & 1.9 & 14.2 & 2.3 & 0.001 & 11.3 & 3.5 & 12.5 & 3.4 & 0.053 \\
\hline ve-Pve & 9.6 & 2.0 & 11.2 & 2.0 & 0.003 & 10.3 & 1.9 & 11.7 & 2.0 & 0.002 & 9.0 & 3.4 & 9.5 & 3.2 & 0.120 \\
\hline$p-P p$ (MPS) & 10.2 & 2.3 & 11.3 & 2.3 & 0.031 & 10.9 & 1.7 & 12.1 & 2.0 & 0.002 & 11.1 & 3.3 & 10.9 & 2.9 & 0.526 \\
\hline IPS & 11.2 & 2.4 & 10.9 & 2.4 & 0.272 & 10.6 & 2.5 & 11.4 & 2.2 & 0.023 & 11.9 & 4.9 & 12.2 & 4.2 & 0.504 \\
\hline eb-Peb & 14.4 & 2.9 & 15.4 & 2.3 & 0.073 & 13.6 & 2.4 & 14.4 & 2.7 & 0.062 & 13.3 & 4.3 & 13.1 & 4.4 & 0.507 \\
\hline OA & 21354 & 4387 & 24362 & 4724 & 0.010 & 22566 & 5245 & 25238 & 3796 & 0.028 & 22936 & 9030 & 23347 & 8596 & 0.859 \\
\hline \multicolumn{16}{|l|}{ Hyoid bone } \\
\hline H-MP & 13.5 & 4.4 & 13.6 & 4.5 & 0.574 & 14.5 & 6.0 & 15.5 & 3.4 & 0.231 & 13.9 & 5.2 & 14.7 & 5.5 & 0.507 \\
\hline $\mathrm{H}-\mathrm{SN}$ & 101.2 & 9.3 & 104.6 & 8.6 & 0.001 & 102.8 & 9.4 & 99.6 & 8.1 & 0.066 & 93.9 & 6.1 & 96.8 & 7.5 & 0.083 \\
\hline $\mathrm{C} 3-\mathrm{H}$ & 33.5 & 4.1 & 34.6 & 3.8 & 0.004 & 33.2 & 2.6 & 33.6 & 2.4 & 0.325 & 28.3 & 5.3 & 31.1 & 3.5 & 0.058 \\
\hline \multicolumn{16}{|l|}{ Head posture } \\
\hline SNCVT $\left({ }^{\circ}\right)$ & 103.7 & 9.2 & 103.6 & 9.6 & 0.733 & 105.4 & 5.0 & 105.6 & 6.5 & 0.849 & 105.4 & 8.1 & 104.9 & 8.5 & 0.790 \\
\hline SNOPT $\left({ }^{\circ}\right)$ & 102.0 & 8.6 & 101.9 & 9.2 & 0.670 & 104.2 & 5.5 & 103.9 & 6.2 & 0.756 & 103.8 & 10.5 & 103.5 & 8.6 & 0.722 \\
\hline
\end{tabular}

RH-ND: Reverse headgear normodivergent; RH-HD: Reverse headgear hyperdivergent; CNT: control group.

SD: standard deviation; NA: nasopharyngeal area; $O A$ : oropharyngeal area.

${ }^{*} p<0.05 ;{ }^{* *} p<0.01 ;{ }^{* *} p<0.0001 ; p>0.05$, non-significant. 
a significance level of 0.05 . There were increases in facial height, nasopharyngeal height, NA and OA dimensions (Table 1).

Observation period changes: Both jaws came forward, declaring a significant decrease in ANB $(\mathrm{p}<0.05)$, and increases in Co-A $(\mathrm{p}<0.05)$ and Go-Gn $(p<0.01)$ were found. The mandibular plane angle decreased significantly $(p<0.05)$. Only nasopharyngeal height increased significantly (S-PNS, Pm'-SPL; $\mathrm{p}<0.05)$.

Comparison of changes between groups: The increase in SNB was more prominent in the control group, showing counterclockwise rotation of the mandible during the observation period compared to the treatment groups (Table 2). The treatment groups showed significant improvements in ANB in

Table 2. Comparison of the changes between treatment and control groups.

\begin{tabular}{|c|c|c|c|c|c|c|c|c|c|}
\hline \multirow{2}{*}{ Measurements } & \multicolumn{2}{|c|}{ RH-ND group (1) } & \multicolumn{2}{|c|}{ RH-HD group (2) } & \multicolumn{2}{|c|}{ CNT group (3) } & \multirow[b]{2}{*}{$1-2$} & \multirow[b]{2}{*}{$1-3$} & \multirow[b]{2}{*}{$2-3$} \\
\hline & Mean & SD & Mean & SD & Mean & SD & & & \\
\hline \multicolumn{10}{|c|}{ Skeletal morphology } \\
\hline $\operatorname{SNA}\left({ }^{\circ}\right)$ & 2.2 & 1.2 & 1.7 & 1.1 & 2.3 & 1.6 & & & \\
\hline $\mathrm{SNB}\left({ }^{\circ}\right)$ & 0.0 & 1.2 & -0.4 & 0.9 & 2.8 & 1.9 & & $* * *$ & $* * *$ \\
\hline $\operatorname{ANB}\left({ }^{\circ}\right)$ & 2.2 & 0.4 & 2.4 & 0.3 & -0.6 & 1.0 & & $* * *$ & $* * *$ \\
\hline CoA & 4.3 & 1.6 & 4.9 & 2.4 & 1.8 & 1.5 & & $*$ & $*$ \\
\hline CoGn & 3.7 & 2.0 & 4.1 & 2.7 & 3.7 & 2.7 & & & \\
\hline $\operatorname{SNGoGn}\left({ }^{\circ}\right)$ & 0.9 & 0.9 & -0.5 & 1.1 & -1.5 & 2.3 & & $* *$ & \\
\hline $\mathrm{SN}-\mathrm{PP}\left({ }^{\circ}\right)$ & -0.9 & 1.0 & -1.0 & 1.2 & 0.1 & 1.1 & & & \\
\hline N-ANS & 0.8 & 1.2 & 1.5 & 1.4 & 0.1 & 1.7 & & & \\
\hline ANS-Me & 4.1 & 1.9 & 1.6 & 1.5 & 1.0 & 2.1 & $* *$ & $* *$ & \\
\hline $\mathrm{N}-\mathrm{Me}$ & 4.9 & 2.5 & 2.9 & 2.5 & 0.8 & 2.9 & & $* *$ & \\
\hline \multicolumn{10}{|l|}{ Nasopharynx } \\
\hline S-PNS & 2.0 & 1.5 & 1.5 & 1.8 & 1.6 & 1.6 & & & \\
\hline ad1-PNS & 2.5 & 1.1 & 1.3 & 1.7 & 0.6 & 2.3 & & $*$ & $*$ \\
\hline ad2-PNS & 2.4 & 1.8 & 1.7 & 1.4 & 0.4 & 1.5 & & * & $*$ \\
\hline$A A^{\prime}-P m^{\prime}$ & 1.1 & 1.2 & 1.2 & 1.0 & -0.4 & 1.4 & & & \\
\hline$P m^{\prime}-S P L$ & 0.9 & 1.7 & 1.6 & 1.8 & 2.5 & 1.6 & & & \\
\hline NA & 1480 & 1262 & 785 & 974 & -1041 & 494 & & * & \\
\hline \multicolumn{10}{|l|}{ Oropharynx } \\
\hline AA-PNS & 1.2 & 1.1 & 0.8 & 1.1 & 0.6 & 1.4 & & & \\
\hline SPS & 1.7 & 0.6 & 1.4 & 0.7 & 1.2 & 1.5 & & & \\
\hline ve-Pve & 1.5 & 0.7 & 1.4 & 0.7 & 0.4 & 1.4 & & & \\
\hline p-Pp (MPS) & 1.1 & 0.8 & 1.1 & 0.7 & -0.1 & 1.3 & & * & $*$ \\
\hline IPS & -0.4 & 0.8 & 0.9 & 0.8 & 0.2 & 2.0 & & & \\
\hline eb-Peb & 0.9 & 0.9 & 0.8 & 0.9 & -0.4 & 1.9 & & & \\
\hline OA & 3007 & 1563 & 2672 & 1570 & 4116 & 375 & & & \\
\hline \multicolumn{10}{|l|}{ Hyoid bone } \\
\hline H-MP & 0.2 & 1.5 & 0.9 & 2.0 & 0.8 & 2.3 & & & \\
\hline $\mathrm{H}-\mathrm{SN}$ & 3.4 & 3.1 & -3.2 & 6.1 & 2.9 & 2.8 & & & \\
\hline $\mathrm{C} 3-\mathrm{H}$ & 1.1 & 1.4 & 0.4 & 0.8 & 2.8 & 2.0 & & & $*$ \\
\hline \multicolumn{10}{|l|}{ Head posture } \\
\hline $\mathrm{SNCVT}\left({ }^{\circ}\right)$ & -0.1 & 3.2 & 0.3 & 2.0 & -0.5 & 3.5 & & & \\
\hline SNOPT $\left({ }^{\circ}\right)$ & -0.1 & 3.1 & -0.3 & 2.0 & -0.4 & 4.1 & & & \\
\hline
\end{tabular}

RH-ND: Reverse headgear normodivergent; RH-HD: Reverse headgear hyperdivergent; CNT: control group.

$\mathrm{SD}$ : standard deviation; NA: nasopharyngeal area; $\mathrm{OA}$ : oropharyngeal area.

${ }^{*} p<0.05 ;{ }^{* *} p<0.01 ;{ }^{* * *} p<0.0001 ; p>0.05$, not significant. 
relation to the control group $(\mathrm{p}<0.01)$. The treatment also induced favorable increases in Co-A $(\mathrm{p}<0.05)$. Facial height and mandibular plane angle increased in the RH-ND group in comparison to other groups. NA showed a significant difference between RH-ND and the control group ( $\mathrm{p}<0.05)$, and MPS showed a difference between the treatment and control groups $(\mathrm{p}<0.05)$.The hyoid bone is positioned more forward in the control group in comparison to the RH-HD group $(\mathrm{p}<0.05)$.

In the correlation analysis, the airway measurements were selected as dependent variables: SNA, SNB, SN-GoGn, H-MP, H-SN, C3-H, SN-CVT and SN-OPT were considered as independent variables. For the RH-ND group, the changes in H-MP and C3-H showed significantly positive effects on $\mathrm{OA}(\mathrm{r}=0.596, \mathrm{p}=0.012$; $r=0.484, p=0.049$, respectively). In the RH-HD group, while the change in SN-GoGn had a significantly negative effect on NA $(r=-0.545, p=0.024)$, SN-CVT and $\mathrm{SN}-\mathrm{OPT}$ have significantly positive effects on IPS $(r=0.585, p=0.014 ; r=0.516, p=0.034$, respectively $)$. In the control group, $\mathrm{SN}-\mathrm{OPT}$ showed a significantly positive effect on MPS $(r=0.606, p=0.048)$.

\section{Discussion}

Recently, 3D images have become used for evaluating airway dimensions. ${ }^{19}$ There is no doubt that 3D images would be preferable, but we believe that archives of two dimensional (2D) cephalometrics are still reliable for evaluating treatment effects, and they are reproducible and cheaper. Due to the retrospective design of this study and to ethical and economic limitations, we used cephalometric data. The ADA Council on Scientific Affairs recommended scientists to follow the "As Low As Reasonably Achievable (ALARA)" principle, which includes taking radiographs based on the patients' needs. ${ }^{20}$ Additionally, the association between 2D and 3D measurements was demonstrated. ${ }^{21}$

Our results showed that both treatment groups induced significant advancement of the maxilla associated with larger amounts of maxillary growth and the inhibition of sagittal mandibular growth with respect to the control group, consistent with previous studies reporting maxillary protraction between 1-3 mm. ${ }^{1,4}$ The mandible showed significant counterclockwise rotation and protrusion in the control group compared to the treatment groups.

No significant changes in airway parameters were found between the normodivergent and hyperdivergent groups in short term. The differences in mandibular rotation, which might implicitly cause an adverse effect on sagittal airway dimensions, exhibited no significant difference, which was consistent with a previous study. ${ }^{22}$ Due to the counterclockwise rotation of the palatal plane in the high angle group, the expected vertical changes in the mandibular plane angle did not occur, which might explain why we were not able to find intergroup differences. Current correlation analysis showed an inverse correlation between NA and the mandibular plane angle in the RH-HD group, consistent with Freitas et al. ${ }^{23}$ who found that vertical growth patterns influenced upper airway dimensions. Confirming this point, Celikoglu et al. ${ }^{24}$ found that the nasopharyngeal and oropharyngeal airway volume were significantly higher in the low-and normal-angle groups than in the high-angle group. Ucar and Uysal ${ }^{16}$ also reported a decrease in nasopharyngeal airway space from low-angle to normal- to high-angle cases.

There are conflicting results in the literature regarding the effects of maxillary protraction with or without maxillary expansion therapy on the sagittal airway dimensions. ${ }^{2,45,6,16}$ According to current results, the nasopharyngeal dimensions representing the adenoid area demonstrated significant increases in the treatment groups compared to the control group, as in previous studies. ${ }^{2,5,25}$ This point might be related to the physiological growth pattern of the lymphoid tissue. ${ }^{26}$ Based on the knowledge that the mean size of the adenoids continues to increase until puberty with a gradual decline afterwards, ${ }^{27}$ the adenoid tissue was approximately at its growth peak at the ages of the treated subjects in this study. Therefore, the existence of a direct favorable effect of RH treatment on the nasopharyngeal airway dimensions could not be concluded, and the size of adenoids, which are age-dependent, should be considered when evaluating the results.

Present analysis revealed a positive correlation between head posture and oropharyngeal airway in the RH-HD and control groups, in line with a previous study. ${ }^{4}$ Yagci et al. ${ }^{6}$ also found increased airway dimensions and cranial flexion of the natural head 
position after expansion and protraction of the maxilla. Again, a positive correlation between the hyoid position and the oropharyngeal area in the RH-ND group was found in this study, declaring a more forward hyoid positioning after protraction. Accordingly, Muto et al.$^{28}$ found correlations between the pharyngeal airway and the hyoid position, jaw sizes, maxillary and mandibular prognathism, and mandibular inclination. The hyoid position represents tongue posture and function, and hyoid structures are guided to an anterio-inferior position to avoid compromising the vital airway passage as a compensatory action. ${ }^{29}$

\section{References}

1. Mermigos J, Full CA, Andreasen G. Protraction of the maxillofacial complex. Am J Orthod Dentofacial Orthop. 1990 Jul;98(1):47-55.

2. Mucedero M, Baccetti T, Franchi L, Cozza P. Effects of maxillary protraction with or without expansion on the sagittal pharyngeal dimensions in Class III subjects. Am J Orthod Dentofacial Orthop. 2009 Jun;135(6):777-81.

3. Toffol LD, Pavoni C, Baccetti T, Franchi L, Cozza P. Orthopedic treatment outcomes in Class III malocclusion. A systematic review. Angle Orthod. 2008 May;78(3):561-73.

4. Hiyama S, Suda N, Ishii-Suzuki M, TsuikiS, Ogawa M, SuzukiS, et al. Effects of maxillary protraction on craniofacial structures and upper airway dimension. Angle Orthod.2002 Feb;72(1):43-7.

5. Sayınsu K, Işık F, Arun T. Sagittal airway dimension following maxillary protraction: a pilot study. Eur J Orthod. 2006 Apr;28(2):184-9.

6. Yagci A, Uysal T, Usumez S, Orhan M. Effects of modified and conventional facemask therapies with expansion on dynamic measurement of natural head position in Class III patients. Am J Orthod Dentofacial Orthop. 2011 Nov;140(5):e223-31.

7. Park SH, Yu HS, Kim KD, Lee KJ, Baik HS. A proposal for a new analysis of craniofacial morphology by 3-dimensional computed tomography. Am J Orthod Dentofacial Orthop. 2006 May;129(5):600.e23-34.

8. Aboudara C, Nielsen I, Huang JC, Maki K, Miller AJ, Hatcher D. Comparison of airway space with conventional lateral headfilms and 3-dimensional reconstruction from conebeam computed tomography. Am J Orthod Dentofacial Orthop. 2009 Apr;135(4):468-79.

9. Battagel JM, L'Estrange PR. The cephalometric morphology of patients with obstructive sleep apnoea. Eur J Orthod. 1996 Dec;18(6):557-69.

10. Tangugsorn V, Skatvedt O, Krogstad O, Lyberg T. Obstructive sleep apnoea: a cephalometric study. Part I.

\section{Conclusion}

No significant differences were found for pharyngeal airway dimensions among different vertical skeletal patterns in Class III patients after short-term maxillary protraction.

When compared with the control subjects, the nasopharyngeal airway at the adenoid region was increased after maxillary protraction, which should be considered based on age, and the oropharyngeal airway suddenly declared advancement, at the level of the soft palate.

Cervico-craniofacial skeletal morphology. Eur J Orthod. 1995 Feb;17(1):45-56.

11. Güven $O$, Saraçoğlu U. Changes in pharyngeal airway space and hyoid bone positions after body ostectomies and sagittal split ramus osteotomies. J Craniofac Surg. 2005 Jan;16(1):23-30.

12. Eggensperger N, Smolka W, Iizuka T. Long-term changes of hyoid bone position and pharyngeal airway size following mandibular setback by sagittal split ramus osteotomy. J Craniomaxillofac Surg. 2005 Apr;33(2):111-7.

13. Lee Y, Chun YS, Kang N, Kim M. Volumetric changes in the upper airway after bimaxillary surgery for skeletal class III malocclusions: a case series study using 3-dimensional cone-beam computed tomography. J Oral Maxillofac Surg. 2012 Dec;70(12):2867-75.

14. Ramesh BV, Vinod N, Murugesan K. Pharyngeal airway changes following mandibular setback surgery. Indian J Dent Res. 2005 Oct-Dec;16(4):147-50.

15. Joseph AA, Elbaum J, Cisneros GJ, Eisig SB. A cephalometric comparative study of the soft tissue airway dimensions in persons with hyperdivergent and normodivergent facial patterns. J Oral Maxillofac Surg. 1998 Feb;56(2):135-9; discussion 139-40.

16. Ucar FI, Uysal T. Orofacial airway dimensions in subjects with Class I malocclusion and different growth patterns. Angle Orthod. 2011 May;81(3):460-8.

17. Greulich WW, Pyle SI. Radiographic atlas of skeletal development of the hand and wrist. 2nd.ed.Redwood City: Stanford University Press;1959.43-96p.

18. Roberts CA, Subtelny JD. An American Board of Orthodontics case report. Use of the face mask in the treatment of maxillary skeletal retrusion. Am J Orthod Dentofacial Orthop. 1988 May;93(5):388-94.

19. Kim YJ, Hong JS, Hwang YI, Park YH. Three-dimensional analysis of pharyngeal airway in preadolescent children with different anteroposterior skeletal patterns. Am J Orthod Dentofacial Orthop. 2010 Mar;137(3):306.e1-11; discussion 306-7. 
20. Patcas R, Signorelli L, Peltomäki T, Schätzle M. Is the use of the cervical vertebrae maturation method justified to determine skeletal age? A comparison of radiation dose of two strategies for skeletal age estimation. Eur J Orthod. 2013 Oct;35(5):604-9.

21. Vizzotto MB, Liedke GS, Delamare EL, Silveira HD, Dutra $\mathrm{V}$, Silveira HE. A comparative study of lateral cephalograms and cone-beam computed tomographic images in upper airway assessment. Eur J Orthod. 2012 Jun;34(3):390-3.

22. Tuncer BB, Kaygısız E, Tuncer C, Yüksel S. Pharyngeal airway dimensions after chin cup treatment in Class III malocclusion subjects. J Oral Rehab. 2009 Feb;36(2):110-7.

23. Freitas MR, Alcazar NM, Janson G, Freitas KM, Henriques JF. Upper and lower pharyngeal airways in subjects with Class I and Class II malocclusions and different growth patterns. Am J Orthod Dentofacial Orthop. 2006 Dec;130(6):742-5.

24. Celikoglu M, Bayram M, Sekerci AE, Buyuk SK, Toy E. Comparison of pharyngeal airway volume among different vertical skeletal patterns: a cone-beam computed tomography study. Angle Orthod. 2014 Sep;84(5):782-7.
25. Baccetti T, Franchi L, Mucedero M, Cozza P. Treatment and post-treatment effects of facemask therapy on the sagittal pharyngeal dimensions in Class III subjects. Eur J Orthod. 2010 Jun;32(3):346-50.

26. Linder-Aronson S, Leighton BC. A longitudinal study of the development of the posterior nasopharyngeal wall between 3 and 16 years of age. Eur J Orthod. 1983 Feb;5(1):47-58.

27. Preston CB, Tobias PV, Salem OH. Skeletal age and growth of the nasopharynx in the sagittal plane: a cephalometric study. Semin Orthod. 2004 Mar;10(1):16-38.

28. Muto T, Yamazaki A, Takeda S, Kawakami J, Tsuji Y, Shibata $\mathrm{T}$, et al. Relationship between the pharyngeal airway space and craniofacial morphology, taking into account head posture. Int J Oral Maxillofac Surg. 2006 Feb;35(2):132-6.

29. Yamaoka M, Furusawa K, Uematsu T, Okafuji N, Kayamoto D, Kurihara S. Relationship of the hyoid and posterior surface of the tongue in prognathism and micrognathia. J Oral Rehabil. 2003 Sep;30(9):914-20. 